\title{
Pesquisa na Sala de Aula de Química: narrativas das aprendizagens da docência partilhada
}

\author{
Research in the Chemistry Classroom: narratives of learning \\ shared teaching
}

\author{
Ana Luiza Alves Constantino (analuizaconstantino@gmail.com) \\ Aluna da Escola de Química e Alimentos - EQA, Universidade Federal do Rio Grande - FURG \\ Aline Machado Dorneles (lidorneles26@gmail.com) \\ Professora da Escola de Química e Alimentos - EQA, Universidade Federal do Rio Grande - \\ FURG \\ Cezar Soares Motta (cezarsmott@gmail.com) \\ Professor de Química da Rede Estadual de Ensino de Rio Grande - RS, Secretaria Estadual de \\ Educação de Rio Grande - RS \\ Aline Silva Dos Santos (aline.quim@gmail.com) \\ Professora de Química da Rede Estadual de Ensino de Rio Grande - RS, Secretaria Estadual de \\ Educação de Rio Grande - RS
}

Resumo: Relata-se a experiência em planejar e desenvolver um júri simulado no ensino de Química, com alunos do $3^{\circ}$ ano do Ensino Médio de uma Escola Pública. As experiências apresentadas se referem à atuação de acadêmicos e professores da Escola e Universidade no Programa Institucional de Bolsa de Iniciação à Docência, subprojeto Química do curso de Química Licenciatura da Universidade Federal do Rio Grande. Neste contexto, foi abordada a problemática fictícia da permanência ou não de uma refinaria de petróleo localizada na área urbana da cidade. Os alunos foram separados em dois grupos: contra ou favor da permanência dessa refinaria. Realizou-se a simulação de um tribunal na sala de aula, com o propósito de oportunizar um ensino de Química permeado por momentos de questionamento, construção de argumentos e comunicação. Dialoga-se com os pressupostos da Pesquisa em Sala de Aula e enfoque da Ciência, Tecnologia e Sociedade a partir dos aprendizados e reflexões de uma prática educativa e da constituição do ser professor de Química, por meio das escritas narrativas dos integrantes deste projeto. O processo de documentar a experiência de fazer Pesquisa em Sala de Aula oportunizou ao coletivo compreender o seu fazer docente, e assim refletir, teorizar e construir conhecimento.

Palavras-chave: CTS; júri simulado; escrita narrativa.

Abstract: We report the experience in planning and developing a simulated jury in Chemistry teaching, with students of the 3rd year of high school in a Public School. The experiences presented refer to the performance of academics, teachers and professors in the Institutional Program of Initiation to Teaching, subproject Chemistry of the Degree in Chemistry of the Federal University of Rio Grande. In this context, the fictitious 
problematic of permanence or not an oil refinery was located in the urban area of the city was addressed. The students were separated into two groups: for or against the permanence of this refinery. A simulation of a court was held in the classroom, with the purpose of providing a Chemistry teaching permeated by moments of questioning, argument construction and communication. Dialoguing with the assumptions of Classroom Research and the focus of Science, Technology and Society, from the learning and reflections of an educational practice and the constitution of being a Chemistry teacher, through the narrative writings of project members. The process of documenting the experience of doing Classroom Research has provided the collective with an opportunity to understand their teaching skills and to reflect, theorize and build knowledge.

Keywords: STS; simulated jury; narrative writing.

\section{INTRODUÇÃO}

Apresentamos a experiência pedagógica vivenciada no ensino de Química por meio dos pressupostos teóricos e metodológicos da Pesquisa em Sala de Aula relacionados ao enfoque da Ciência, Tecnologia e Sociedade (CTS), e assim fomentar o questionamento, a construção de argumentos e a comunicação, proporcionando aos alunos realizarem pesquisa (SANTOS; SCHNETZLER, 1997; GALIAZZI, 2003).

O ensino de Química visa formar sujeitos críticos que compreendam os conceitos desta disciplina como necessários para sua participação efetiva na sociedade científicotecnológica em que se vive. Assim, almejamos uma educação para cidadania, para isso é preciso educar para democracia (SANTOS; SCHNETZLER, 1997). Diante disto, compreendemos ser necessário saber exercer a capacidade de escolha e a construção de argumentos frente às questões que abarcam a Ciência e a Tecnologia. Para existir uma sociedade democrática é necessária à participação ativa de cidadãos capazes de exercer seu papel de forma crítica diante das questões políticas.

De acordo, com Santos e Schnetzler (1997), destacamos o objetivo do estudo CTS, de desenvolver a tomada de decisão. Assim, este conceito "relaciona-se à solução de problemas da vida real que envolve aspectos sociais, tecnológicos, econômicos e políticos, o que significa preparar o indivíduo para participar ativamente na sociedade democrática" (SANTOS; SCHNETZLER, 1997, p. 68).

Ao pensarmos em problemáticas com enfoque CTS, também buscamos pensar os diferentes setores da sociedade envolvidos, de modo a favorecer a efetiva participação dos estudantes na pesquisa, possibilitando que ponham em prática suas decisões e a 
construção de argumentos frente ao conjunto de questões que permeiam uma determinada temática.

Entendemos que as atividades nessa perspectiva permitem aos alunos viabilizarem a oportunidade de questionar e se posicionarem diante de um problema presente no cotidiano, de construir argumentos para defender seus pontos de vistas e, ao final, comunicar aos demais a posição perante a problemática apresentada.

Nesse sentido, relacionamos a discussão da Ciência, Tecnologia e Sociedade aos pressupostos da Pesquisa em Sala de Aula, buscando viabilizar o desenvolvimento de uma situação simulada através da atividade de "júri simulado". E, assim promover o questionamento, a construção de argumentos sobre o estudo proposto e a comunicação das aprendizagens desenvolvidas pelos alunos. Nesse sentido, concordamos com Moraes, Ramos e Galiazzi (2004):

\begin{abstract}
A pesquisa em sala de aula pode ser compreendida como um movimento dialético, em espiral, que inicia com o questionar dos estados do ser, fazer e conhecer dos participantes, construindo-se a partir disso novos argumentos que possibilitam atingir novos patamares desse ser, fazer e conhecer, estágios esses então comunicados a todos participantes do processo (MORAES; RAMOS; GALIAZZI, 2004, p. 11).
\end{abstract}

Compreendemos, então, que o questionamento, a produção de argumentos e a comunicação formam um conjunto que constitui uma espiral que nunca é acabada. Desse modo, a cada ciclo que se passa, atingimos novos patamares de ser, compreender e fazer (MORAES; RAMOS; GALIAZZI, 2004). Na Pesquisa em Sala de Aula, os estudantes exercem a autonomia nas ações e interações nos grupos de trabalho, o coletivo se constitui e aprende com cada um dos sujeitos que estão ali (GALIAZZI, 2003).

A perspectiva CTS aponta a importância do não menosprezar, no processo educacional, o querer conhecer, assim tem sido traçado um novo horizonte: de aprender participando. Em uma sociedade contemporânea, é impossível a compreensão de tudo para depois se integrar. Diante deste novo direcionamento, o aprendizado acontece no processo de busca pelas respostas, de encaminhamentos para problemas contemporâneos, na ressignificação da experiência vivida, ou seja, uma situação existencial (AULER, 2007). 
Desse modo, partilhamos a experiência de planejar e desenvolver um júri simulado no ensino de Química, nas Rodas de Formação semanais do Programa Institucional de Iniciação à Docência - PIBID/Química na Universidade Federal do Rio Grande - FURG, com a participação da professora supervisora da Escola parceira, dos acadêmicos bolsistas e da professora coordenadora. Em diálogo com os estudantes do $3^{\circ}$ ano do Ensino Médio, emergiu a possibilidade de abordarmos uma temática pertinente ao contexto vivido por eles: a presença de uma refinaria de petróleo nas proximidades da Escola. Tal situação permitiu o planejamento e desenvolvimento de uma atividade baseada em um júri simulado com a problemática de permanência desta refinaria de petróleo localizada na comunidade local. A experiência foi documentada pelo viés da escrita narrativa, com a intenção de compreender nossas práticas docentes de modo à ressignificá-las, para que, possamos possibilitar uma maior reflexão e interpretação do espaço da sala de aula e suas atividades.

O PIBID/Química da FURG orienta suas ações nas Escolas e na Universidade a partir dos pressupostos teóricos da Pesquisa Narrativa em Rodas de Formação e na Pesquisa em Sala de Aula (SOUZA, 2011; GALIAZZI, 2003). Apostamos na escrita narrativa como modo de construir, reconstruir e documentar nossas aprendizagens da docência e na partilha dessas experiências com o outro (MORAES, RAMOS; GALIAZZI, 2004; DORNELES; GALIAZZI, 2012). Dessa forma, o presente trabalho tem como objetivo compreender as experiências docentes vividas no processo de planejar e desenvolver coletivamente uma proposta de júri simulado no ensino de Química.

\section{METODOLOGIA}

A atividade foi desenvolvida com dez alunos do $3^{\circ}$ ano do Ensino Médio, na faixa etária de 16 a 19 anos de idade, de uma Escola da Rede Estadual localizada no município de Rio Grande - RS, como ação do projeto PIBID/Química da FURG. A atividade foi promovida com a professora supervisora e quatro acadêmicas bolsistas.

A experiência da docência partilhada emerge nos processos de planejamento coletivo durante os encontros semanais de formação em Rodas no PIBID/Química. Nas Rodas, os acadêmicos bolsistas em conjunto com os professores supervisores e a coordenadora, partilhavam suas experiências de sala de aula. Desse modo, a partir das 
vivências e da realidade local da Escola parceria, emergiu a possibilidade de construir uma situação simulada contextualizando o papel da refinaria de petróleo, sua permanência e consequências para moradores da região, visto que, a mesma está localizada na área urbana do município de Rio Grande - RS em proximidade à Escola.

As Rodas de Formação do PIBID contribuíram na escrita desta problemática em formato de notícia em jornal, bem como com ideias para desenvolver a atividade. $\mathrm{O}$ planejamento foi disposto da seguinte forma: A turma do $3^{\circ}$ ano do Ensino Médio foi separada em dois grupos para a simulação de um tribunal com intuito de levantar prós e contras à presença da refinaria de petróleo na área urbana do munícipio. Apresentamos aos alunos a seguinte problemática:

Domingo pela manhã, moradores da região próximo da refinaria são surpreendidos por um alarme falso, porém, dias depois, relatam a presença de fuligem e um odor intenso resultando no mal-estar de muitos. Possível vazamento de gases tóxicos na refinaria? A chama apagou, e o alarme tocou. O que fazer?

Destacamos, conforme Santos (1992), a importância da escolha de temas/problemas sociais para que estimulem os estudantes em suas decisões por meio do enfoque CTS:

\footnotetext{
A inclusão dos temas sociais é recomendada por todos os artigos revisados, sendo justificada pelo fato de eles evidenciarem as interrelações entre os aspectos da ciência, tecnologia e sociedade e propiciarem condições para o desenvolvimento nos alunos de atitudes de tomada de decisão (SANTOS, 1992, p. 139).
}

Nesse sentido, a atividade de promover um júri simulado propicia aos alunos exercerem suas escolhas. Pensamos que a atividade se mostra importante também por estarem cursando o $3^{\circ}$ ano do Ensino Médio, concluindo sua trajetória na Educação Básica, e, por consequência, precisam estar preparados para sua nova jornada fora da Escola.

O jornal construído nas Rodas de Formação do PIBID/Química foi entregue aos estudantes, participantes dessa pesquisa, abordando a situação simulada, e apresentando também informações, como, por exemplo, a história e a presença da refinaria na cidade do Rio Grande. 
Ao final da apresentação da proposta, os estudantes tiveram o prazo de duas semanas para entregar a parte escrita da atividade e realizar a apresentação do júri simulado. Como parâmetro de avaliação, a professora supervisora em conjunto com as acadêmicas bolsistas do PIBID decidiram que os alunos, para obterem um bom desempenho na atividade, deveriam demonstrar uma boa defesa de seus argumentos, juntamente com embasamento abrangendo a Química e utilizando os conhecimentos adquiridos em sala de aula. Assim, os estudantes deveriam utilizar todos os seus conhecimentos químicos para defender seus pontos de vista.

Nesse sentido, destacamos Moraes, Ramos e Galiazzi (2004):

\begin{abstract}
A pesquisa em sala de aula precisa do envolvimento ativo e reflexivo permanente de seus participantes. A partir do questionamento é fundamental pôr em movimento todo um conjunto de ações, de construção de argumentos que possibilitem superar o estado atual e atingir novos patamares do ser, do fazer e do conhecer (MORAES; RAMOS; GALIAZZI, 2004, p. 16).
\end{abstract}

Compreendemos que é necessária a importância inicial do questionamento para que possa ser feita a construção de um argumento, e desse modo, iniciar a sua comunicação. O júri simulado foi composto pelos seguintes componentes: um juiz, quatro jurados e os representantes do lado a favor e do contrário a permanência da refinaria. O lado a favor foi composto por dois advogados, um empresário, um pesquisador e dois trabalhadores. E do lado contrário, dois advogados, um morador e um ambientalista.

Assumimos, então, que ao desenvolver problemáticas como a atividade proposta, os estudantes assumem o papel de mediadores, cabendo a eles organizar perguntas emergentes sobre o tema, promover o debate, a pesquisa, leitura e escrita. Assim, os participantes reconstroem seus saberes iniciais, ressignificando seus questionamentos a partir dos conhecimentos científicos adquiridos durante o processo e assumindo o papel de construtores do conhecimento ao tornarem-se atores na proposta (GALIAZZI et al., 2004).

O planejamento e desenvolvimento do júri simulado foram partilhados nos encontros semanais de formação do PIBID/Química, bem como, no processo de escrita narrativa realizado no portfólio coletivo dos professores supervisores e acadêmicos bolsistas. O portfólio coletivo permite que cada pibidiano escreva sua experiência, 
sendo um espaço partilhado de leitura, de alteridade e de aprendizagens de planejar com o outro. O professor supervisor e o coordenador também escrevem no portfólio, reforçando um processo de formação horizontal entre os pares.

Os processos de construção de um portfólio reflexivo e de formação de professores possuem na escrita para aquele que relata a oportunidade de vivenciar, registrar, lembrar e refletir momentos relacionados à formação. Nos registros e reflexões sobre sua escrita no portfólio, o professor reorganiza suas atividades, e assim, relembra o seu tempo de Escola, onde associa às lembranças e emoções de vivências como aluno, potencializando os aprendizados que dizem respeito aos seus alunos, à Escola e à sala de aula contribuindo na formação docente (FIRME; GALIAZZI, 2014).

Conforme Firme e Galiazzi (2014):

A escrita no portfólio coletivo possibilita o desenvolvimento do trabalho em grupo, a partilha de ideias e, principalmente, a construção da responsabilidade de cada participante na elaboração desse mesmo portfólio. É uma possibilidade de formação em grupo, que depende do compromisso de cada participante que nele escreve, lê e reescreve, favorecendo, assim, a discussão no grupo das experiências vivenciadas na escola e nos encontros presenciais do PIBID durante o processo de formação inicial e continuada, articulando a universidade e a escola básica (FIRME; GALIAZZI, 2014, p.146).

A escrita narrativa no portfólio coletivo perpassou por todos os envolvidos no processo de planejar e desenvolver a atividade. A narrativa pode ser compreendida como modo de construir conhecimento através das experiências que nos acontecem. Diante disso, a formação de professores de Química se torna uma experiência a partir dos acontecimentos vividos e dos significados que eles transmitem para quem os viveu, no entanto, é necessário refletir como se é afetado pelo vivido (DORNELES, 2016).

Essas escritas possibilitam detalharmos as nossas vivências em sala de aula e compartilhar as experiências, de modo que, possamos melhorar a nossa prática docente. Dorneles e Galiazzi (2012) propõem a narrativa como modo de investigar a sala de aula e atuação docente, e afirmam que:

No ato de investigar o espaço escolar e a atuação docente por meio da pesquisa narrativa, os professores, no referido processo de formação, podem narrar experiências, fatos, ações que significam sua sala de aula como problematizadora e formativa. Em outros momentos, podem narrar situações problemáticas, para as quais não encontram respostas; fazem perguntas; e partilham com o outro, no sentido de ouvir o que ele vivência na sua sala de aula. A escrita narrativa promove a mediação; o acolhimento; o espaço para 
expressar as experiências; os sentimentos e os dilemas da vida profissional e do ser professor (DORNELES; GALIAZZI, 2012, p. 258).

O portfólio com as escritas narrativas de três licenciandas, da professora supervisora e da professora coordenadora se tornou material de pesquisa dos próprios sujeitos que viveram a experiência de sala de aula. Fundamenta-se na Pesquisa Narrativa o caminho teórico e metodológico da investigação. Como pesquisadores narrativos trabalhamos com nossos participantes e com nós mesmos, significando que nos tornamos visíveis com nossas próprias histórias vividas e contadas (CLANDININ; CONNELLY, 2011).

A Pesquisa Narrativa é uma forma de caracterizar os fenômenos da experiência humana. É tanto o fenômeno que se investiga, como o método de investigação (CONNELLY; CLANDININ, 1995). Desse modo, buscamos compreender e interpretar as experiências docentes vividas a partir da seguinte pergunta: quais experiências de sala de aula são narradas no processo de planejar e desenvolver coletivamente uma proposta de atividade de um júri simulado no ensino de Química? Desse modo, as interpretações construídas no processo de análise de cada narrativa, levam a compreender as experiências docentes e argumentar sobre a importância do PIBID como espaço de aprendizagens e de construção de uma docência partilhada, entre a Escola e a Universidade.

\section{AS EXPERIÊNCIAS E REFLEXÕES DA DOCÊNCIA PARTILHADA}

Os alunos participaram da atividade mostrando pleno interesse na proposta desenvolvida, além disso, estavam caracterizados em seus personagens, vestidos de advogado, pesquisador, administrador, assim como os demais personagens presentes neste júri. Utilizaram recursos didáticos, como por exemplo, livros didáticos de Química e sites na Internet, para fortalecer os seus argumentos e defender seus pontos de vista, quando questionados por outro colega com uma visão contrária a sua. A seguir, destacamos o trecho da narrativa da pibidiana que reforça o envolvimento dos alunos na atividade:

Eis que chegou o grande dia, os alunos chegaram vestidos de advogados, ambientalistas, gerentes incorporando os seus personagens. A sala onde ocorreu o debate dispunha de televisão para os alunos utilizarem algum material que tinham trazido. Os alunos se utilizaram de todo material estudado para o debate, trazendo notícias e reportagens sobre os benefícios 
e malefícios de uma refinaria no centro da cidade. Além disso, todos os alunos mostraram-se entusiasmados a baterem os argumentos de seus concorrentes. $O$ tempo de $2 \mathrm{~h} /$ aula pareceu pouco para terminarem o debate, eles estavam realmente determinados a defenderem os seus pontos de vista. Ao final da aula, nós pibidianas e a professora recebemos argumentos bastante positivos sobre a atividade, inclusive os alunos gostariam de realizar a mesma atividade em uma outra oportunidade (Acadêmica bolsista do PIBID/Química da FURG, 2017).

A narrativa ressalta o debate realizado, o envolvimento dos estudantes frente à problemática e a tomada de decisão. Percebemos a construção de argumentos sendo exercida quando são questionados e provocados a pensar e defender seus pontos de vista. O questionamento tem um maior significado quando é construído a partir de uma nova compreensão, valor ou atitude e, devido a isso, entende-se o "perguntar" como movimento inicial de uma pesquisa (MORAES; RAMOS; GALIAZZI, 2004). Acreditamos que os alunos aprendem quando atribuem significado naquilo que foi estudado, desse modo, o questionamento é o primeiro passo para realizar a Pesquisa em Sala de Aula. Assim, a atividade do júri simulado impulsionou os estudantes a se questionarem mais sobre um determinado assunto, pois, para construir uma opinião a respeito, é necessário conhecer de maneira profunda sobre o tema em estudo.

Defendemos que os sujeitos envolvidos no processo de aprendizagem ao questionar e problematizar sua realidade se apropriam de maneira significativa dos conceitos estudados (MORAES; RAMOS; GALIAZZI, 2004). Com isso, a proposta de um júri simulado foi pertinente, devido à localização da Escola ser próxima à refinaria e seus alunos residirem nas redondezas, desse modo, os questionamentos partiram de suas realidades. Conforme Moraes, Ramos e Galiazzi (2004), o segundo momento da pesquisa é:

É preciso envolver-se na produção para produzir argumentos, como por exemplo, pesquisar em livros, procurar pessoas e realizar experimentos e também analisar e interpretar os diferentes pontos de vistas e ideias. E por fim, expressar os resultados em forma de produção que normalmente é a escrita (MORAES; RAMOS; GALIAZZI, 2004, p. 17).

Entendemos que os alunos ao se envolverem na atividade para produzir seus argumentos, realizaram a pesquisa, necessitando conhecer mais sobre o assunto tratado. Dessa forma, solicitamos aos estudantes uma produção escrita como parte da avaliação 
e registro das suas aprendizagens. De acordo com Moraes, Ramos e Galiazzi (2004), destacamos o momento da comunicação:

É importante que a pesquisa em sala de aula atinja um estágio de comunicar resultados, de compartilhar novas compreensões, de manifestar novo estado do ser, do fazer e do conhecer, o que contribui para a sua validação na comunidade em que esse processo está se dando (MORAES; RAMOS; GALIAZZI 2004, p. 19).

Salientamos a etapa de comunicação, primeiramente, como um esforço de expressar a construção e reconstrução da aprendizagem, e num segundo momento, para divulgação dos resultados do trabalho (MORAES; RAMOS; GALIAZZI, 2004). Em nossa atividade na Escola, a comunicação por parte dos alunos se deu em dois momentos: o primeiro, com a expressão dos argumentos para a turma e demais presentes; o segundo, ao divulgar os resultados obtidos a partir da escrita sobre a atividade.

Evidenciamos também a perspectiva CTS dialogada com as proposições defendidas por Paulo Freire, quando buscamos envolver temas que permeiam a sociedade de modo a tornar os participantes mais conscientes de suas realidades (FREIRE, 1998). A aproximação com Freire pode ser percebida por algumas características presentes em nossa atividade, como a problematização e o diálogo. Podemos definir a problematização presente ao propor um júri simulado, e favorecer um trabalho coletivo por meio do diálogo entre professores e estudantes. O trecho descrito no trabalho de Auler, Dalmolin e Fenalti (2009) defende a relação dos pressupostos de Paulo Freire com a atividade descrita nesse trabalho:

(...) considerando que Freire propõe e pratica uma nova relação entre currículo e realidade local. Entre o 'mundo da escola' e o 'mundo da vida'. Estas duas dimensões, praticamente incomunicáveis na concepção hegemônica de escola, aqui, interagem, uma influenciando a outra. $\mathrm{O}$ 'mundo da vida' adentra no 'mundo da escola', nas configurações curriculares, através do que este educador denominou de temas geradores, os quais envolvem situações problemáticas, contraditórias. Estes carregam, para dentro da escola, a cultura, as situações problemáticas vividas, os desafios enfrentados pela comunidade local. O mundo vivido, os problemas e as contradições nele presentes passam a ser o ponto de partida. Nos temas geradores, originados localmente, manifestam-se as contradições da estrutura social mais ampla. Estes representam o ponto de partida para, a partir destes, ampliar e alcançar uma visão global da sociedade (AULER; DALMOLIN; FENALTI, 2009, p. 75). 
Concordamos com o trecho descrito, visto que, o ensino tradicional se distância das situações reais vivenciadas por alunos, professores e comunidade do entorno da Escola, fixando apenas em conteúdos programáticos. Neste trabalho, escolhemos uma situação simulada partindo do contexto local, já que a refinaria faz parte da vida dos moradores próximos à Escola. Acreditamos que trazer situações como essa à sala de aula, possibilita contextualizar e dar um significado maior ao Ensino de Química.

Diante disso, mencionamos que os pressupostos da Pesquisa em Sala de Aula e a discussão CTS foram grandes alicerces da atividade desenvolvida. As três bases da Pesquisa em Sala de Aula: o questionamento, a construção de argumentos e a comunicação fizeram parte da atividade desenvolvida. Os pressupostos CTS contribuíram para que pudéssemos pensar em uma problemática que envolvesse a vivência dos alunos da Escola.

Quando propusemos a Pesquisa em Sala de Aula, nós professores em formação fomos convidados a viver a investigação educativa, assim nos desafiamos a compreender a aula como fenômeno a ser investigado, por meio da escrita narrativa no portfólio coletivo, com a intenção de partilhar nossas experiências. O fragmento narrativo da professora coordenadora retrata essa aposta:

Contar as experiências de um trabalho coletivo não é tarefa fácil, pois afinal quando somos coletivos? E, quando somos um grupo? Penso que o trabalho em grupo pode vir a ser um coletivo, quando os sujeitos se colocam como aprendentes com o Outro. A reflexão acima encaminha minha narrativa reflexiva das experiências de um grupo que vem se constituído num coletivo. O olhar de cada um para as experiências que constroem no coletivo é diferente, por isso reforço a importância do portfólio coletivo oportunizar a aprendizagem da docência construídas e reconstruídas com os outros (Professora coordenadora do PIBID/Química da FURG, 2017).

A narrativa favorece o exercício da alteridade, como também, caráter dialógico que possui quando explorada no processo educativo, em especial, como modo de investigar a sala de aula. Assim, os próprios licenciandos quando exercerem a aprendizagem da docência podem promover a escrita narrativa na construção do conhecimento. As narrativas se tornam conteúdo da formação de professores (GONÇALVES; FERNANDES, 2010).

A seguir destacamos as narrativas de uma licencianda e da professora regente da turma que participaram da atividade: 
Fazer parte do júri simulado foi uma experiência inovadora para minha formação como licencianda. A atividade do júri nas escolas são uma ótima estratégia de ensino e aprendizado, faz com que a turma se envolva num processo de investigar o assunto problematizado, trazendo os conceitos de Química de forma reflexiva e dinâmica. Atividades como essa vão estar presentes nas minhas futuras aulas, onde percebi o envolvimento da turma e desenvolvimento do senso crítico desses estudantes (Acadêmica bolsista do PIBID/Química da FURG, 2017).

Em relação à participação dos alunos na atividade, pude perceber o envolvimento e dedicação dos alunos na realização desta, pois demonstraram conhecimento e entendimento sobre o assunto. Isto me deixou muito feliz e orgulhosa, enquanto educadora! Pude perceber também que realizando atividades como essa, o aluno adquire mais autonomia e, com isso, torna-se capaz de resolver mais facilmente problemas dentro e fora do contexto educacional, e aprende a ter mais criticidade quanto ao que pensa e produz. Um aspecto negativo quanto à realização desta atividade, para mim, foi o curto período de tempo que atrapalhou a conclusão do trabalho. Mesmo assim, conseguimos concluir meio que às pressas. O importante é que no final deu tudo certo! (Professora supervisora da Escola, 2017).

A licencianda narra à importância que essa experiência trouxe a sua formação como futura professora considerando a atividade como uma estratégia viável de ensino, sendo possível aprender Química de forma reflexiva e dinâmica. Nesse contexto, a estudante também ressalta que pretende realizar atividades como essa em suas futuras aulas.

A narrativa da professora supervisora aponta uma maior autonomia dos alunos, graças ao contexto em que a atividade foi desenvolvida, permitindo que esses estudantes exercessem um pensamento crítico. De acordo com a professora, a atividade deveria ser realizada em maior tempo. Esta consideração contribui na elaboração de futuros planejamentos envolvendo atividades semelhantes em sala de aula. A narrativa da professora se aproxima do registro da licencianda que narra à presença de um forte senso crítico na atividade. Para nós, professores, é um desafio à conciliação entre o tempo e a atividade, já que as Escolas dispõem de uma carga horária pequena para o ensino de Química. Assim, destacamos que o planejamento de uma aula é uma etapa essencial para proporcionar um bom aprendizado aos alunos. Percebemos, também, o interesse dos estudantes em prosseguir com a atividade como é demonstrado nas narrativas, sendo um dos indícios que esta proposta foi bem-sucedida.

As experiências de sala de aula documentada de modo narrativo oportunizaram as licenciandas, a professora supervisora e a professora coordenadora a partilha das aprendizagens da docência no PIBID/Química. Assim, reforçamos a importância da 
escrita narrativa no processo de formação de professores de Química, proporcionado na partilha das histórias de sala de aula: a presença do licenciando, a experiência de vivenciar momentos de aprender e ensinar o exercício da docência (DORNELES; GALIAZZI, 2012). Desse modo, o processo de documentar a experiência de fazer Pesquisa em Sala de Aula oportuniza ao professor compreender o seu fazer docente, e assim refletir, teorizar e construir conhecimento. Assim, a escrita de narrativa se tornou um caminho para documentar e comunicar nossas aprendizagens e reflexões da prática docente.

\section{CONSIDERAÇÕES FINAIS}

O trabalho foi realizado de forma participativa por todos presentes na sala de aula. A importância da temática abordada faz parte do cotidiano de muitos estudantes que residem próximo à refinaria e os fatores que isso acarreta. O trabalho teve como enfoque a abordagem da Química de forma contextualizada, assim tornando uma experiência com potencial de aflorar o interesse dos alunos. A atividade relatada favoreceu a conexão dos conhecimentos iniciais dos alunos e de seus conhecimentos científicos.

A atividade proposta de um júri simulado foi uma prática que proporcionou aos estudantes relacionar seus conhecimentos químicos para defender e produzir argumentos sobre a permanência ou não de uma refinaria de petróleo localizada na área urbana da cidade do Rio Grande, no estado do Rio Grande do Sul.

A experiência relatada oportuniza desenvolver a habilidade de tomada de decisão dos alunos a partir dos pressupostos da Ciência, Tecnologia e Sociedade (CTS), como também, o diálogo, a argumentação e a comunicação pela Pesquisa em Sala de Aula. O conjunto dessas competências proporcionou criticidade dos estudantes em seus debates diante do desenvolvimento do exercício da cidadania.

Nesse sentido, em potenciais trabalhos dentro destas temáticas é possível desenvolver aportes teóricos que construam uma maior aptidão dos estudantes aos conceitos trabalhados em sala de aula como letramento científico, e também, a interdisciplinaridade promovendo um espaço de diálogo e planejamento entre as áreas do conhecimento e seus respectivos professores. 
Reforçamos a importância dos pressupostos da Pesquisa em Sala de Aula, em promover espaços de questionamentos, argumentos e comunicação em sala de aula e da CTS, que proporciona aos alunos realizar aprendizado a partir de problemáticas que estão próximas de suas vivências, bem como, o desenvolvimento de habilidades importantes de cidadania como a tomada de decisões. Além disso, ressaltamos que a aproximação CTS possibilitou refletir sobre o conceito de aprender participando, isto é, além da pesquisa, o aprendizado durante o desenvolvimento da atividade, como por exemplo, a partir de uma conversa que temos com o outro.

Integrar os estudos CTS no planejamento de nossas propostas para a sala de aula possibilitou organizar atividades que permeiam temas/problemas sociais relevantes, entendendo que a complexidade desta abordagem não é alcançada por via unicamente disciplinar. Foi importante escutar e respeitar as vivências dos alunos na comunidade ao redor da Escola, e assim relacionar a temática a suas histórias aos conceitos científicos de Química.

A realização desta atividade foi gratificante para todos do nosso grupo, sendo esta, a primeira experiência para alguns participantes em planejar e desenvolver uma aula. $\mathrm{O}$ ambiente proporcionado pelo PIBID/Química da FURG compreendeu um espaço coletivo de pesquisa, intensificando a parceria Universidade e Escola. Por meio de nossas escritas narrativas, tantos os professores como licenciandos passaram a refletir sobre sua prática docente, documentando as vivências e aprendizagens que foram significativas, assim, compreendendo de melhor forma nossas experiências pedagógicas. Atividades desenvolvidas pelo nosso grupo em nossas Rodas de Formação como: o diálogo, a escrita narrativa e a reflexão propiciaram a investigação educativa e a docência partilhada, fomentando a relevância do PIBID na formação acadêmica e a decisão pela profissão escolhida.

\section{REFERÊNCIAS}

AULER, D. Enfoque Ciência - Tecnologia - Sociedade: pressupostos para o contexto brasileiro. Ciência \& Ensino, v.1. Número especial, 2007.

AULER, D.; DALMOLIN, A. M. T.; FENALTI, V. S. Abordagem Temática: natureza dos temas em Freire e no enfoque CTS. ALEXANDRIA Revista de Educação em

Ciência e Tecnologia, v. 2, n. 1, p. 67-84, 2009. 
CLANDININ, D. J.; CONNELLY, F. M. Pesquisa narrativa: experiência e história em pesquisa qualitativa. Tradução: Grupo de Pesquisa Narrativa e Educação de Professores ILEEI/UFU. Uberlândia: EDUFU, 2011.

CONNELLY, F. M.; CLANDININ, D. J., Relatos de Experiencia e Investigación Narrativa. In: LARROSA, J.; FERRER,V.; LARA, N. P.; CONNELLY, F. M.; CLANDININ, D. J. Déjame que te Cuente - Ensayos sobre Narrativas y Educación. Barcelona: Ed. Laertes, 1995, p. 10-59.

DORNELES, A. M. Rodas de investigação narrativa na formação de professores de química: pontos bordados na partilha de experiências. 2016. 113 folhas. Tese: (Doutorado em Educação em Ciências: Química da Vida e da Saúde) - Associação Ampla FURG/UFRGS/UFSM - Universidade Federal do Rio Grande - FURG, Rio Grande, 2016.

DORNELES, A. M.; GALIAZZI, M. C. Histórias de Sala de Aula de Professoras de Química: Partilha de Saberes e de Experiências nas Rodas de Formação do PIBID/FURG. Química Nova na Escola, v. 34, n 4, p. 256-265, 2012.

FIRME, M. V. F.; GALIAZZI, M. C. A Aula Experimental Registrada em Portfólios Coletivos: A Formação Potencializada pela Integração entre Licenciandos e Professores da Escola Básica. Química Nova na Escola, v. 36, n. 2, p. 144-149, 2014.

FREIRE, P. Pedagogia do Oprimido. $25^{\text {a }}$ ed. Rio de Janeiro: Paz e Terra, 1998. GALIAZZI, M. C. Educar pela pesquisa: ambiente de formação de professores de Ciências. Ijuí: Unijuí, 2003.

GALIAZZI, M. C.; GARCIA, F.; LINDEMANN, R.; GRUPO MIRAR. Construindo Caleidoscópios - organizando unidades de aprendizagem. In: MORAES, R. (org.); MANCUSO, R. (org.). Educação em Ciências: produção de currículos e formação de professores. Ijuí: Unijuí, 2004. p. 65-84.

GONÇALVES, F.; FERNANDES, C. Narrativas acerca da prática de ensino de química: um diálogo na formação inicial de professores. Química Nova na Escola, v. 32, n. 2, p. 121-127, 2010.

MORAES, R.; RAMOS, M. G.; GALIAZZI, M. C. Pesquisa em Sala de Aula: fundamentos e pressupostos. In: MORAES, R.; LIMA, V. M. D. (orgs). Pesquisa em sala de aula: tendências para a Educação em novos tempos. Porto Alegre: EDIPUCRS, 2 ed., 2004, p 10-23.

SANTOS, W. L. P. O Ensino de Química para Formar o Cidadão: Principais Características e Condições para a sua Implantação na Escola Secundária Brasileira. Campinas: UNICAMP. 1992. 233 folhas. Dissertação. (Mestrado em Educação), Faculdade de Educação, Universidade de Campinas, 1992.

SANTOS, W. L.; SCHNETZLER, R. P. Educação em Química: compromisso com a cidadania. Ijuí: Editora Unijuí, 1997.

SOUZA, M. L. Histórias de professores de química em rodas de formação em rede: colcha de retalhos tecida em partilhas (d)e narrativas. Ijuí: Unijuí, 2011. 